\title{
Published Papers about Interior Design from South East Europe in the Scopus Database (1977 - 2015)
}

\author{
Elena Nikoljski Panevski ${ }^{1}$, Aleksandar Petanovski ${ }^{2}$, Ivo Spiroski ${ }^{3 *}$ \\ ${ }^{1}$ Faculty of Design and Technology of furniture and interior, Ss Cyril and Methodius University of Skopje, Republic of Mace- \\ donia; ${ }^{2}$ Faculty of Architecture, Ss Cyril And Methodius University of Skopje, Republic of Macedonia; ${ }^{3} I D-D e s i g n$ \\ 2012/DOOEL Skopje, Republic of Macedonia
}

Citation: Nikoljski Panevski E, Petanovski A, Spiroski Published Papers about Interior Design from South East Europ Nov Scopus Database (1977 - 2015). SEE J Archit Des. 2015 10.3889/seejad.2015.10007

Key words: interior design; Scopus database; citation metrics: South East Europe; Republic of Macedonia.

Correspondence: MSc Eng Ivo Spiroski. ID Desig . $13 / 451000$ Skopje. E(id-press.eu

Received: 13-Oct-2015; Revised: 07-Nov-2015; Accepted: 8-Nov-2015; Published: 09-Oct-2015

Copyright: () 2015 Elena Nikoljski Panevski, Aleksandar Petanovski, lvo Spiroski. This is an open-access article distributed under the terms of the Creative Commons Attribution License, which permits unrestricted use, distribution, and

Competing Interests: The author have declared that no competing interests exis.

\begin{abstract}
AIM: The aim of this study was to analyse current scientific impact of Published Papers about Interior Design from South East Europe in the Scopus Database (1977-2015).

MATERIAL AND METHODS: Title search of the Scopus database was performed on October 02, 2015 about interior design from South East Europe in the Scopus Database (1960-2014). A total number of 5,808 documents worldwide were identified with "interior design" in the title, abstract or keywords. By limitation to South East European countries (Albania, Bosnia and Herzegovina, Bulgaria, Croatia, Cyprus, Greece, Kosovo, Moldova, Macedonia, Montenegro, Romania, Serbia, Slovenia, Turkey, and Italy) only 151 documents were separated $(2.6 \%$ of all documents). Selected documents were analysed by year, source, author, country/territory, document type, and subject area.

RESULTS: The number of publication in the period of 1977-2005 year was very small and was increased with maximum of 19 papers in 2011 year. Three academic journals published most of the papers: Medicina Del Lavoro (14 papers); Work and Design Principles (5 papers), and Practices (4 papers). The biggest number of papers belongs to the author Nicoletti S with 6 papers, followed by Di Leone G, Carino M, Trani G, and Yildirim K (5 papers each). Universities from Turkey and Italy are dominant institutions which published academic papers. Prevalence of the published papers about interior design from South East Europe in the Scopus Database (1977-2015) was from Italy (67 papers), Turkey (55 papers), and Croatia (10 papers). Most of the documents published about Interior Design from South East Europe were articles and conference papers. Subject area medicine was predominant followed by engineering, social sciences, and others.
\end{abstract}

CONCLUSION: Officials of the academic institutions in South East European countries should undertake more effective and proactive policies in order to include more journals in the Scopus database.

\section{Introduction}

Southeast Europe or South Eastern Europe is a geographical and political region of Europe, consisting primarily of the Balkan Peninsula. Sovereign states that are generally included in South Eastern Europe are, in alphabetical order, Albania, Bosnia and Herzegovina, Bulgaria, Croatia, Cyprus, Greece, Kosovo, Moldova, Macedonia, Montenegro, Romania, Serbia, Slovenia, and partially Turkey and Italy. These boundaries can vary greatly due to the political, economic, historical, cultural, and geographic considerations of the observer [1].

Interior design is the art or process of designing the interior, often including the exterior, of a room or building. An interior designer is someone who coordinates and manages such projects. Interior design is a multifaceted profession that includes conceptual development, communicating with the stakeholders of a project and the management and execution of the design. Interior design is the process of shaping the experience of interior space, through the manipulation of spatial volume as well as surface treatment [2].

Interior designer implies that there is more of an emphasis on planning, functional design and the effective use of space, as compared to interior decorating. An interior designer can undertake projects that include arranging the basic layout of spaces within a building as well as projects that require an understanding of technical issues such as window and door positioning, acoustics, and lighting [1]. Although an interior designer may create the layout of a space, they may not alter load-bearing walls without having their designs stamped for approval by an architect. Interior designers often work directly with architectural firms. 
Scopus is the world's largest abstract and citation database of peer-reviewed literature with smart tools that track, analyze and visualize research. Easy to use and comprehensive, Scopus is designed to quickly find the information researchers' need. Scopus indexes over 20,500 titles from 5,000 publishers worldwide; contains 49 million records, $78 \%$ with abstracts; includes over 5.3 million conference papers [3]. Scopus includes a more expanded spectrum of journals than Web of Science, and its citation analysis is faster and includes more articles than the citation analysis of Web of Science. On the other hand, the citation analysis that Web of Science presents provides better graphics and is more detailed than the citation analysis of Scopus, probably because Web of Science has been designed with the intention of satisfying users in citation analysis, a field discussed and debated by scientists for decades [4].

The three databases [Web of Science (WoS) Scopus, and Google Scholar] represent different approaches to citation search services. WoS and Scopus are commercial databases (at the expensive end of the spectrum - for good reasons). Google Scholar is currently an open access database, still in beta version after its launch in November 2004. The expectations are different for fee-based and free databases, but open access should not provide excuse for illconceived and poorly implemented search options, and for convoluted, and potentially misleading presentation of information [5].

The aim of this study was to analyze current scientific impact of Published Papers about Interior Design from South East Europe in the Scopus Database (1977-2015).

\section{Material and Methods}

Title search of the Scopus database was performed on October 02, 2015 in order to analyze current scientific impact of published papers about interior design from South East Europe in the Scopus Database (1977-2015). Only the topic "interior design" was used for selection of published papers in SCOPUS database.

A total number of 5,808 documents worldwide were identified with "interior design" in the title, abstract or keywords. By limitation to South East European countries (Albania, Bosnia and Herzegovina, Bulgaria, Croatia, Cyprus, Greece, Kosovo, Moldova, Macedonia, Montenegro, Romania, Serbia, Slovenia, Turkey, and Italy) only 151 documents were separated (2.6\% of all documents). Selected documents were analyzed by year, source, author, country/territory, document type, and subject area.

\section{Results}

The number of publication in the period of 1977-2005 year was very small (1-3 papers per year). Starting of 2006 year, the number of published papers was increased with maximum of 19 papers in 2011 year (Fig. 1).

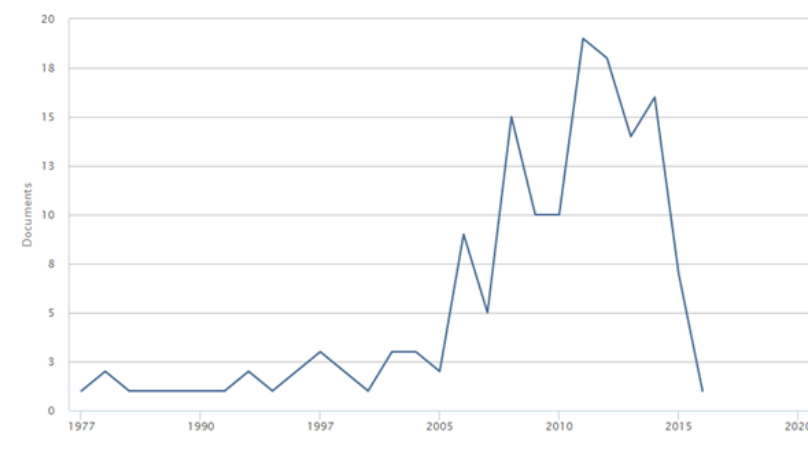

Figure 1: Current scientific impact of Published Papers about Interior Design from South East Europe in the Scopus Database (19772015)

The largest number of papers from South East Europe were published in Medicina Del Lavoro (14 papers), followed by Work (5 papers), Design Principles and Practices (4 papers), Collegium Antropologicum (3), Applied Ergonomics (3 papers), and Tekstilec ( 3 papers). Eight journals published 2 papers each, and the rest of journals published only one paper each (Fig. 2).

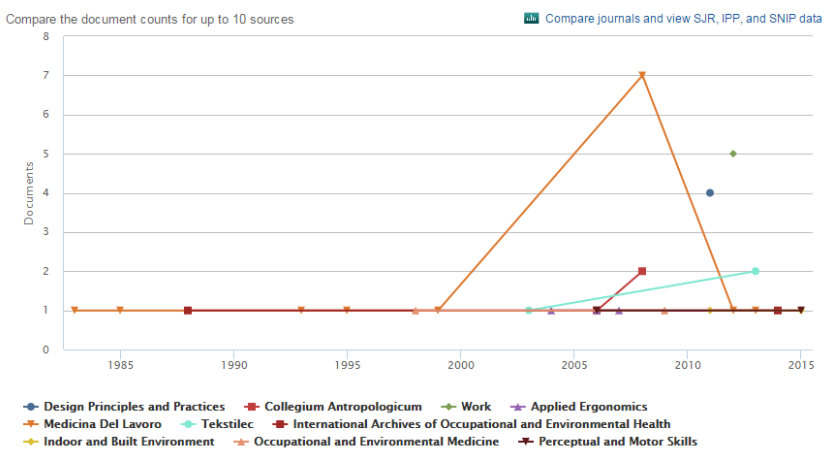

Figure 2: Current documents per year by source about Interior Design from South East Europe in the Scopus Database (1977-2015)

The number of papers published by top ten authors is shown in Figure 3. First places belongs to Nicoletti S with 6 papers, four authors published 5 papers each (Di Leone G, Carino M, Trani G, and Yildirim K). Three authors published 3 papers each (Colombini D, Ambrosi L, and Barli O). The rest of the authors published two or one paper each (Fig. 3).

Eight papers were published from Gazi Universitesi, seven papers were published by Politecnico di Milano, six papers from Universita Ca'Foscari Venezia, and Universite degli Studi di Foggia. The rest of the institutions from South East Europe published five 
or less papers during the studied period. Five papers were published from Bilkent Universitesi and Universita degli Studi di Roma La Sapienza (Fig. 4, left).

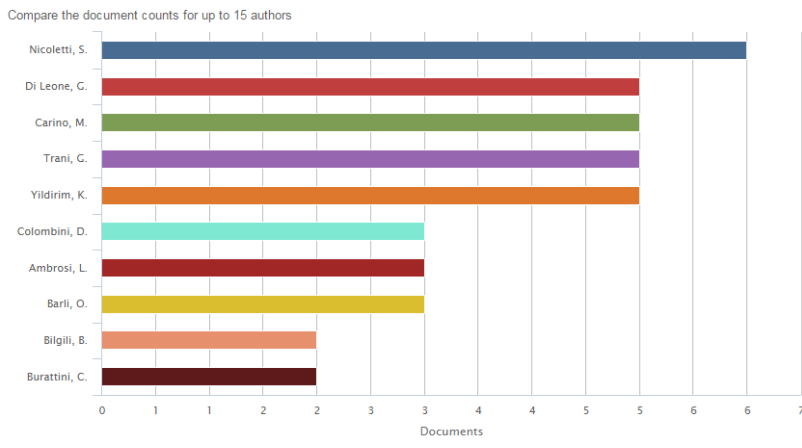

Figure 3: Current number of published papers by author about Interior Design from South East Europe in the Scopus Database (1977 2015)

Most of the papers about Interior Design from South East Europe in the Scopus Database (19772015) were published from Italy (67 papers), Turkey (55 papers), and Croatia (10 papers). The rest of the countries published less than five papers in total (Fig. 4 , right).
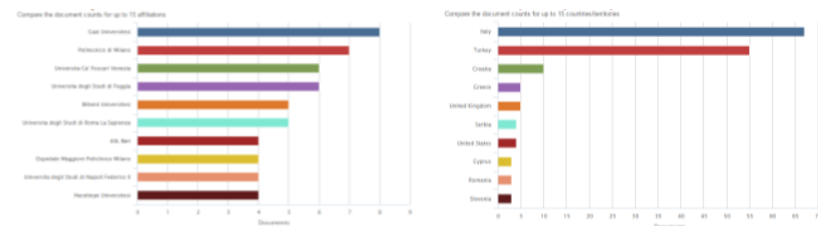

Figure 4: Current documents by affiliation (left) and current documents by country (right) about Interior Design from South East Europe in the Scopus Database (1977-2015)

Most of the documents published about Interior Design from South East Europe were articles (99 or $65.6 \%$ ). Conference papers were published in one quarter (38 papers or $25.2 \%$ ), Reviews were published less than $10 \%$ (11 papers or $7.3 \%$ ). The rest of the documents were published less than one per cent. (Fig. 5, left). Subject area medicine was predominant (52 documents or $34.4 \%$ ) followed by engineering (49 papers or $32.5 \%$ ), social sciences (33 papers or $21.9 \%$ ), environmental science (19 papers or $12.6 \%$ ), arts and humanities (18 papers or $11.9 \%$ ), and computer science (17 papers or $11.3 \%$ ). All other subjects were published less than $10 \%$ (Fig. 5, right).
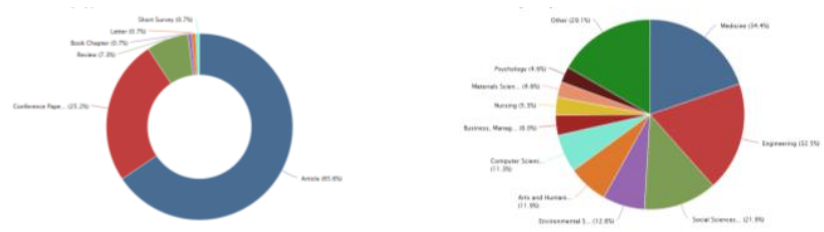

Figure 5: Current percentage of documents by type (left) and current percentage of documents by subject area (right) about Interior Design from South East Europe in the Scopus Database (19772015)

\section{Discussion}

In this paper we presented published papers about interior design from South East Europe in the Scopus database from 1977 to 2015 year. The number of publication in the period of 1977-2005 year was very small and was increased with maximum of 19 papers in 2011 year. Three academic journals published most of the papers: Medicina Del Lavoro (14 papers); Work and Design Principles (5 papers), and Practices (4 papers). La Medicina del Lavoro is a bimonthly journal founded in 1901 by L. Devoto, and directed after him by L. Prieti and E. Vigliani. Now directed by $\mathrm{V}$. Foà (Milan), is the oldest and most prestigious Italian journal in such field. Its aim is training and updating of occupational medicine specialists and physicians involved in occupational diseases, industrial hygiene and in the prevention and treatment of occupational diseases. The target of the journal is represented by occupational medicine specialists, company doctors and medical officers of local health services of Occupational Medicine. The impact factor for 2015 was calculated as 0.554 .

The biggest number of papers belongs to the author Nicoletti $S$ with 6 papers, followed by Di Leone G, Carino M, Trani G, and Yildirim K (5 papers each). The rest of the authors published three or less than three papers each.

It is obvious that Universities from Turkey and Italy are dominant institutions which published academic papers. Gazi Universitesi from Turkey published eight papers, Politecnico di Milano from Italy published seven papers, Universita Ca'Foscari Venezia and Universite degli Studi di Foggia from Italy published six papers. Thus, prevalence of the published papers about interior design from South East Europe in the Scopus Database (1977-2015) was from Italy (67 papers), Turkey (55 papers), and Croatia (10 papers).

Most of the documents published about Interior Design from South East Europe were articles and conference papers. Subject area medicine was predominant followed by engineering, social sciences, and others. Domination of the subject medicine is present in the worldwide publications, because the biggest investments in the facilities are in the medical public and private institutions. Probably because of that, the analysis of Macedonian medical scientific papers in the Scopus database was published stressing the fact that the important factor for increasing the quality of the Macedonian medical journals is validation of the published papers in the journals indexed in the Scopus database, which is associated with submission and/or defence of PhD theses. Such policy would trigger Editorial Boards to improve the quality of their journals and include them in the Scopus database [6].

Australian universities recently received a list 
of journals from the Australian Research Council (ARC). This list was the proposed set of journal rankings for the new Excellence in Research for Australia (ERA) initiative. This list includes journals for design and design research. The ERA journal-ranking proposal is intended to cover all appropriate journals across all fields. Journal rankings for any specific field should represent an appropriate distribution of journals for that field. Journals are described as $A^{*}$ journals representing the top $5 \%$ of journals in a field, $A$ journals representing the next $15 \%$, B journals representing the next $20 \%$, and $C$ journals for all the rest [7]. According this ERA Journal Ranking, only Journal Applied Ergonomics was listed in A, Journal Textilec was listed in $B$, and Journal of Design Principles and Practice was listed in C (more than $20 \%$ of Journal in a field) [7]. It is necessary to make more efforts for inclusion of the journals from the South East Europe in the field of interior design to increase their quality and to be classified in $A^{*}$ or $A$ group.

In the paper of Gemser et al., 2012 [8], the primary objectives was to identify a set of journals that report on industrial design research and to propose quality rankings of those journals. Based on an online survey, design journals were assessed in terms of two quality metrics: popularity and indexed average rank position. They found that both general and specialized design journals were highly valued and that geographic origin and academic background can be related with journal rankings [8]. Thus, regional journal for interior design, as a part of architecture and design, in South East Europe would be beneficial for increase of the popularity and indexed average rank position. SouthEast European Science Advanced through Evaluation (SEESAmE) is an OJS-based journal management system strengthened by certain qualitycontrol functionalities and enriched with: a full text citation database intended for searching and downloading SEESAmE journal articles and other publications; an evaluation tool for ranking journals and related research entities; and an expert database containing detailed profiles of SEESAmE authors to be used as a tool to locate reviewers and research partners in general. Unfortunately only one academic journal from South East Europe (Arhitektura I dizajn, Belgrade, Serbia) is included in this aggregator of scientific information [9].

In the paper published by Chai and Xiao, 2012 [10] they analysed 12035 citations in the 459 articles published in the prestigious journal Design Studies from 1996 to 2010 by using a novel network analysis. It was concluded that the journal Design Studies has indeed become more international (nonEuropean countries have increased their article contribution to Design Studies), Design Studies was found to be the most-cited journal, and the journal's core themes over the past 15 years have been identified as design process and design cognition [10].

Interior design is the art and science of understanding people's behavior to create functional spaces within a building. Decoration is the furnishing or adorning of a space with fashionable or beautiful things. In short, interior designers may decorate, but decorators do not design.

Interior designer implies that there is more of an emphasis on planning, functional design and the effective use of space, as compared to interior decorating. An interior designer can undertake projects that include arranging the basic layout of spaces within a building as well as projects that require an understanding of technical issues such as window and door positioning, acoustics, and lighting [11]. Although an interior designer may create the layout of a space, they may not alter load-bearing walls without having their designs stamped for approval by an architect. Interior designers often work directly with architectural firms.

Types of interior design include residential design, commercial design, hospitality design, healthcare design, universal design, exhibition design and spatial branding. The profession of interior design is relatively new, constantly evolving, and often confusing to the public. It is a creative profession that is consistently changing and evolving. It is not an artistic pursuit and relies on research from many fields to provide a well-trained understanding of how people are influenced by their environments.

From the seven countries of South East Europe (Albania, Bosnia and Herzegovina, Bulgaria, Kosovo, Moldova, Macedonia, Montenegro) there are not published any papers about interior design in the Scopus database (1977 - 2015). The explanation might be smaller number of faculties dealing with interior design in those countries, the smaller number of academic journals published and/or included in Scopus database, as well as inclusion of interior design in other academic fields. Analysis of other database (Web of Science, Google scholar, EMBASE, EBSCO, and others) could possibly show different results from this paper.

Other areas of specialization which include amusement and theme park design, museum and exhibition design, event design (including ceremonies, weddings, baby and bridal showers, parties, conventions and concerts), interior and prop styling, tablescape design, theatre and performance design, stage and set design, and production design for film and television are not covered by this paper.

In summary, a total number of 5,808 documents worldwide were identified with "interior design" in the title, abstract or keywords in the Scopus database. By limitation to South East European countries only 151 documents were separated $(2.6 \%$ of all documents). Selected documents were analyzed by year, source, author, country/territory, document type, and subject area. Officials of the academic institutions in South East European countries should undertake more effective and proactive policies in order to include more journals in the Scopus database. 


\section{References}

1. Hösch E, Nehring K, Sundhaussen H (Hrsg.): Lex-ikon zur Geschichte Südosteuropas. Redaktion Konrad Clewing, Böhlau Wien/UTB Stuttgart, 2004: 776.

2. Ching FD, Binggeli C. Interior design illustrated. John Wiley \& Sons, 2012.

3. Bakkalbasi N, Bauer K, Glover J, Wang L. Three options for citation tracking: Google Scholar, Scopus and Web of Science. Biomed Digit Libr. 2006;3:7

http://dx.doi.org/10.1186/1742-5581-3-7

4. Falagas ME, Pitsouni El, Malietzis GA, Pappas G. Comparison of PubMed, Scopus, Web of Science, and Google Scholar: strengths and weaknesses. FASEB J. 2008:22(2):338-42.

http://dx.doi.org/10.1096/fj.07-9492LSF

5. Jacso P. As we may search-Comparison of major features of the Web of Science, Scopus, and Google Scholar citation-based and citation-enhanced databases. Current Science-Bangalore. 2005;89(9): 1537.

6. Spiroski M. Analysis of Macedonian Medical Scientific Papers in the Scopus Database. Maced J Med Sci. 2013;6(1):5-10.

http://dx.doi.org/10.3889/MJMS.1857-5773.2013.0284

7. Friedman K, Barron D, Ferlazzo S, Ivanka T, Melles G, Yuille J. Design research journal ranking study: preliminary results. 2008.

8. Gemser G, de Bont C, Hekkert P. Quality percep-tions of design journals: The design scholars' per-spective. Design Studies. 2012;33:4-23.

http://dx.doi.org/10.1016/i.destud.2011.09.001

9. SouthEast European Science Advanced through Evaluation (SEESAmE).

http://ceoncees.org/gate/WhatsAndWhys.aspx. Accessed: October 05, 2015.

10. Chai K-H, Xiao X. Understanding design research: A bibliometric analysis of Design Studies (1996-2010). Design Studies. 2012;33:24-43.

http://dx.doi.org/10.1016/j.destud.2011.06.004

11. Pile J. Interior Design. 3rd edn, Pearson: New Jersey, USA, 2003. 